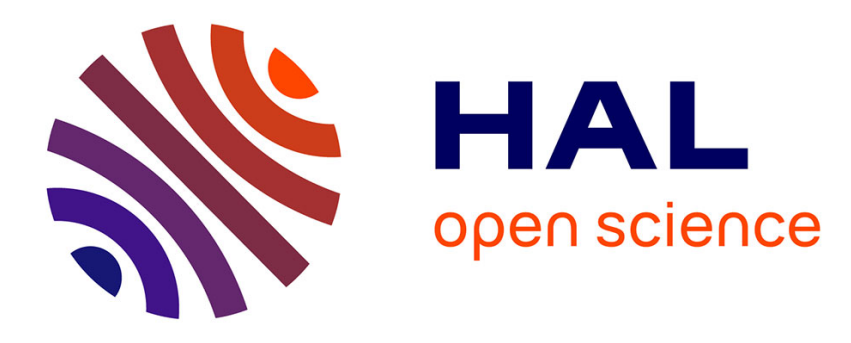

\title{
Widening the body to rubber hands and tools: what's the difference?
}

Frédérique de Vignemont

\section{To cite this version:}

Frédérique de Vignemont. Widening the body to rubber hands and tools: what's the difference?. 2010. ijn_00512313

\section{HAL Id: ijn_00512313 \\ https://hal.science/ijn_00512313}

Preprint submitted on 30 Aug 2010

HAL is a multi-disciplinary open access archive for the deposit and dissemination of scientific research documents, whether they are published or not. The documents may come from teaching and research institutions in France or abroad, or from public or private research centers.
L'archive ouverte pluridisciplinaire HAL, est destinée au dépôt et à la diffusion de documents scientifiques de niveau recherche, publiés ou non, émanant des établissements d'enseignement et de recherche français ou étrangers, des laboratoires publics ou privés. 
Incorporer objets et membres factices: quelle différence?

Widening the body to rubber hands and tools: what's the difference?

de Vignemont Frederique ${ }^{1} \&$ Farnè Alessandro ${ }^{2,3}$

${ }^{1}$ Institut Jean Nicod, UMR 8129, CNRS - EHESS - ENS, Paris, France;

${ }^{2}$ INSERM, UMR-S 864 "Espace et Action," F-69500 Bron, France;

${ }^{3}$ Université Claude Bernard Lyon I, F-69000 Lyon, France.

Auteur correspondant/Corresponding author: de Vignemont F. \& Farnè A 


\title{
Résumé
}

Le cerveau représente le corps de différentes manières (e.g., sensorielle, motrice) pour des fins différentes (e.g., se reconnaître, agir dans l'espace). Depuis un siècle maintenant, neuropsychologues, philosophes et neuroscientifiques ont cherché une définition opérationnelle des représentations du corps, proposant un vaste champ de notions distinctes telles que le schéma corporel, l'image corporelle, etc. Les résultats récents sur la possibilité d'incorporer des corps étrangers n'ont fait qu'ajouter à la complexité. En particulier, en raison de leurs effets sensoriels et moteurs, la main en caoutchouc et les outils peuvent être considérés comme tous deux incorporés, c'est-à-dire qu'ils sont traités comme s'ils faisaient partie du corps. Mais à quel point peut-on élargir la représentation de son corps? Quelles sont les contraintes qui régissent l'incorporation d'objets externes? Et s'agit-il des mêmes selon que l'incorporation est motrice (i.e. objet intégré dans le schéma corporel) ou perceptive (i.e. object intégré dans l'image corporelle)? Nous confrontons ici deux domaines de recherche trop souvent étudiés isolément afin de mieux comprendre les lois de l'incorporation. En particulier, nous analysons les similitudes et les différences entre l'incorporation d'outils et l'incorporation de mains prosthétiques. En conclusion, nous proposons qu'elles correspondent à deux types d'incorporation distincts, régis par des lois différentes, mais que dans les deux cas, l'incorporation n'est que partielle.

\begin{abstract}
The brain represents the body in different ways (e.g., perceptual, motor) for different purposes (recognising oneself, acting in space). Several concepts and even more numerous labels (e.g., body image, body schema) have historically been proposed to define these representations in operational terms. Recent evidence of embodiment of external objects has added complexity to an already quite intricate picture. In particular, because of their perceptual and motor effects, both rubber hands and tools can be conceived as embodied, that is, represented in the brain as if they were parts of one's own body. But are there any limits to what we can embody? What constraints lay upon embodiment? And are they similar both for motor embodiment (i.e. integration within the body schema) and for perceptual embodiment (i.e. integration within the body image)? Here, we consider the implications emerging from the different, and up-to-now relatively separate research domains of tool use and rubber hand illusion for understanding the rules of embodiment. In particular, we compare what the embodiment of tools and prostheses may or may not have in common. We conclude that in both cases, although for different reasons and with different constraints, embodiment is only partial.
\end{abstract}

Mots clés : Image corporelle, schéma corporel, plasticité, utilisation d'outils, illusion de la main en caoutchouc

Key words: body image, body schema, plasticity, tool use, Rubber Hand Illusion 
"The lower animals keep all their limbs at home in their own bodies, but many of man's are loose, and lie about detached, now here and now there, in various parts of the world - some being kept always handy for contingent use, and others being occasionally hundreds of miles away. A machine is merely a supplementary limb; this is the be all and end all of machinery. We do not use our own limbs other than as machines; and a leg is only a much better wooden leg than any one can manufacture. Observe a man digging with a spade; his right fore-arm has become artificially lengthened, and his hand has become a joint." Butler en 1872 [1, p. 267]

\section{INTRODUCTION}

In normal speech, we often refer to tools as parts of the bodily self (e.g., I am parked at the corner of Broadway and Houston). But this may be more than a mere linguistic shortcut. Has it never happened to you to bend your head when driving under a bridge of low height, thus confusing the dimensions of your car with your own bodily dimensions? Does this confusion reveal that tools and machines are "merely supplementary limbs", that is, that they are processed by the brain in the same way as biological arms and legs? What is at stake here is to determine the extent of the plasticity of the representation of one's body. On the basis of recent experimental evidence, it has been claimed that body representations can stretch to include allograft, prostheses, rubber hands, virtual avatars and tools. Hence, what is embodied can be in flesh and blood, in rubber, in metals, or even completely virtual. It may be anatomically shaped or not. It may be controlled, or internally felt, or both. But do all those various phenomena of embodiment involve one and the same mechanism?

Here, we shall focus on the contrast between tool use and the now classic rubber hand illusion (RHI), which has rarely been directly investigated experimentally [2]. Briefly, in the classical set-up of the RHI, participants sit with their left arm resting on a table, hidden behind a screen. They are asked to fixate at a rubber hand presented in front of them, and the experimenter simultaneously strokes with two paintbrushes both the participant's hand and the fake hand. Participants report feeling as if they were touched on the rubber hand and as if 
the rubber hand were part of their body. They mislocate their biological hand in direction of the rubber hand (i.e. proprioceptive drift). Here again, it seems that the rubber hand is "merely a supplementary limb". Yet, a difference between the tool and the rubber hand immediately strikes us: tools are rarely experienced as if they belonged to oneself in the same way as rubber hands do. As Botvinick [3, p. 783] noticed, "the feeling of ownership that we have for our bodies clearly does not extend to, for example, the fork we use at dinner". A further difference is that tools are said to extend the body, while rubber hands are said to be incorporated [4]. Finally, many variations of the original set-up of the RHI have investigated the constraints that lay upon the illusion. Among other findings (see Table 1), they reveal that one cannot induce the illusion if the rubber hand is replaced by a piece of wood or a tool $[5,6]$. In addition to spatio-temporal congruency between the tactile stimulations, it has been suggested that a so-called 'body model' constrains the visual capture of touch [7], and overall the sense of bodily ownership. Although the description of the body model is often left incomplete, a minimal requirement seems to be that it represents a template of the anatomical structure of a human body.

To sum up, we face an apparent paradox. On the one hand, there seems to be a large flexibility of what one can embody that seems to go beyond any anatomical constraints; on the other hand, there seems to be a very narrow window of what can be embodied, highly constrained by the anatomy of the human body. In this paper, we shall review the similarities and differences between the RHI and tool use.

\section{The 'body model' hypothesis}

According to Armel and Ramachandran [8], mere spatio-temporal congruency of visuo-tactile stimulations suffices to induce the RHI, whatever the object visually presented. That would 
suggest that strong statistical correlations between different sensory modalities are sufficient conditions for deceiving our brains and that any object can be processed as if it were a part of one's body (i.e. embodied). However, all the following RHI studies show that there are some further constraints beside mere statistical correlations. In particular, there is no significant difference between asynchronous and synchronous conditions if the visually presented object does not look like a hand. On the basis of such findings, it has been repetitively argued that the RHI is modulated by something like a pre-existing body model, which represents the spatial organization of the body $[7,9,10]$. One can further enlarge this view and defend what we call the body model hypothesis. On this view, embodiment must respect some basic anatomical constraints. Therefore, only some objects under certain circumstances can be processed as if they were parts of one's body.

Although the description of the body model is often left incomplete, a minimal requirement seems to be that it represents a template of the anatomical structure of the human body. This body model corresponds to what has been identified in the philosophical literature as a long-term body image [11], and in the neuropsychological literature as visuo-spatial body representation [12], or body structural description [13]. It represents the long-term properties of one's body such as the spatial configuration and the metrics of body parts (i.e., their boundaries, their proximity and their position relative to each other). The body model plays a structural role in spatially shaping bodily experiences. It is said to be impaired in patients with autototopagnosia, who can no longer point to parts of their body that are named, touched or shown.

Whether one calls it body model, long-term body image or body structural description, it is supposed to determine what can or cannot be embodied. In other words, only objects that meet the description given in the body model can be processed as if they were parts of one's body. In favour of the body model hypothesis, we shall now review the constraints that lay 
upon the RHI, and more specifically the anatomical constraints. They can be summarized as follows (see table 1).

\begin{tabular}{|c|c|c|}
\hline \multicolumn{2}{|c|}{ Constraints } & References \\
\hline Temporal & $\begin{array}{l}\text { Synchronous stimulations } \\
\text { (less than } 300 \mathrm{~ms} \text { delay) }\end{array}$ & $\begin{array}{l}\text { e.g. Botvinick \& Cohen } \\
\text { (1998) [14] } \\
\text { Shimada et al. (2009) [15] }\end{array}$ \\
\hline \multirow{3}{*}{ Spatial } & $\begin{array}{l}\text { Location of } \mathrm{RH} \text { less than } \\
30 \mathrm{~cm} \text { far from } \mathrm{BH}\end{array}$ & e.g. Loyd (2007) [16] \\
\hline & $\begin{array}{l}\text { Position of the } \mathrm{RH} \text { aligned } \\
\text { with } \mathrm{BH}\end{array}$ & $\begin{array}{l}\text { e.g. Pavani et al. (2000) } \\
{[17]} \\
\text { Tsakiris \& } \\
(2005)[10]\end{array}$ \\
\hline & $\begin{array}{l}\text { Direction of stroking } \\
\text { congruent in hand-centred } \\
\text { frame }\end{array}$ & $\begin{array}{l}\text { e.g. Costantini \& Haggard } \\
\text { (2007) [9] }\end{array}$ \\
\hline \multirow{3}{*}{ Anatomical } & Hand-shaped & $\begin{array}{l}\text { e.g. Tsakiris et al. (2010) } \\
\text { [5] }\end{array}$ \\
\hline & Identical hand laterality & $\begin{array}{l}\text { e.g. Tsakiris \& Haggard } \\
(2005)[10]\end{array}$ \\
\hline & $\begin{array}{l}\text { Size of } \mathrm{RH} \text { similar or } \\
\text { bigger than of } \mathrm{BH}\end{array}$ & $\begin{array}{l}\text { e.g. Pavani \& Zampini } \\
\text { (2007) [18] }\end{array}$ \\
\hline
\end{tabular}

Table 1. Constraints that lay upon the RHI (RH: rubber hand; $\mathrm{BH}$ : biological hand)

Based on these results, we can draw two conclusions. On the one hand, there seems to be a clear anatomical constraint such that one can embody only objects that are anatomically identical to the body part that is stroked. Of particular interest for us is the fact that no significant difference between synchronous and asynchronous stroking was found when the rubber hand was replaced by a wooden spoon, or any object that was not looking like a hand. On the other hand, there is no need for objects to be embodied to look like one's own body parts. Indeed, visual similarity between the rubber hand and the biological hand (e.g., skin luminance, the specific shape of the hand) does not affect the RHI [19]. Furthermore, a recent 
study showed the possibility to induce RHI for the whole body (i.e. full-body illusion through virtual reality) for a virtual avatar of a different gender [20]. Hence, the body model does not even seem to prevent gender transfer in full body illusions. The only study that points towards a certain self-specificity shows that there is no RHI if the participants see a rubber hand that is smaller than their own hand [18]. However, there is no influence if the rubber hand is bigger. Hence, we can conclude that to some extent the body model that constrains the RHI is not very fine-grained. It carries information more about the human body in general than about the subject's individual bodily parameters.

Here, we shall propose that there may be even less anatomical constraints upon the RHI than suggested by the body model hypothesis. Arguably, the body model must respect some biological constraints such that for instance, visual information about a left hand cannot be integrated with somatosensory information about a right hand. Another constraint may be that there can be only two hands represented, a left hand and a right hand, and no more. If so, one should expect the embodiment of the rubber hand to be associated with a disembodiment of the biological hand, as if the biological hand were replaced by the artificial counterpart. However, as we shall see now, these two basic anatomical constraints are not always respected by the RHI.

Let us start with the laterality issue. There are two distinct questions that may be raised. First, it has been observed that denial of ownership is largely due to right- compared to leftbrain damage. Is this asymmetry reflected at the level of the RHI? It was shown that when exposed to left and right rubber hands (with respectively their left and right biological hands stroked), neurotypical participants experienced the RHI as comparably vivid, but their skin conductance responses were larger in case of left rubber hands [21]. One way to interpret these results is that one can embody both left and right hands, but the implicit ownership is stronger for left rubber hands. The authors concluded that this asymmetry reflects a right 
hemisphere dominance for the sense of (rubber) body ownership. One may thus speculate that the body model, if body model there is, is localized in the right hemisphere. A second question concerns the laterality constraint. Does laterality difference between the rubber hand and the biological hand impact the RHI? A positive answer to this question was initially offered by Tsakiris and Haggard [10], who found no RHI when a right rubber hand was visually presented while the left biological hand was stroked. However, Petkova and Ehrsson [22] were recently able to induce the RHI with such difference in laterality. A right rubber hand was placed on the table, while the right biological hand was hidden behind a screen. The left biological hand was placed in full view, but participants were instructed to look at the rubber hand. Both the left biological hand and the right rubber hand were stroked. Despite the incongruence between the hand laterality, participants reported feeling touch on the rubber hand and displayed a proprioceptive drift. The only difference with the normal RHI was that it was more difficult to elicit (i.e. longer stimulation time and illusion on less participants). It therefore seems that the RHI violates the hand laterality constraint posited by the body model.

What about the two-hand constraint? That amputees can incorporate a prosthesis is not surprising as it replaces, so to speak, the missing limb. It fills the gap. What is more surprising is that individuals with their already complete body can incorporate a rubber hand as well. One way to account for the RHI is on the model of amputees. In other words, the 'embodied' rubber limb replaces the biological limb so that people experience only two limbs, one of them being fake. As for the biological limb, it becomes temporarily excluded from the body model. Alternatively, one can account of such artificial embodiment on the model of supernumerary limbs. Some patients experience the presence of phantom hands or legs, in addition of their own biological hands and legs. One may suggest that at one level, they represent their own body with three or even four hands or legs. If so, there are some degrees of liberty relative to the anatomical template of the human body. One can embody more than 
two hands. Alternatively, patients with supernumerary limbs may have two distinct body models, one representing the phantom limbs, and the other representing the biological limbs. The body model then respects the two-hand constraint, but it can be duplicated. In any case, both interpretations show that one can embody a supernumerary limb (whether a phantom limb or a rubber limb) at no cost for the biological limbs.

One way to assess the two models of the RHI is to investigate the fate of the biological hand during the RHI. However, the results are controversial. In questionnaires, participants slightly disagree when asked if they felt as if their hand had disappeared $(-0.4$ in the synchronous condition and -0.8 in the asynchronous condition, in [23], negative score representing the level of disagreement and positive score representing the level of agreement), but they also disagree when asked if they felt as if they had three hands $(-1.6$ in the synchronous condition and -1.8 in the asynchronous condition, idem). At the physiological and behavioural level, it was found a decrease in skin temperature of the biological hand following the RHI, as well as a slowing down of tactile processes [24,25]. These results have been interpreted by Moseley and colleagues [24] as evidence that the participant's biological hand is disembodied and replaced by the artificial counterpart. However, similar tactile performance has been found by Folegatti and colleagues [25] following prismatic displacement independently of any disembodiment. Like in the RHI, prismatic displacement involves a cross-modal mismatch between the seen and felt position of the hand. However, unlike the RHI, there is no fake hand involved here, only one's own hand seen at a different location than where it is felt to be located thanks to prismatic goggles. Yet, a similar slowing down of tactile processes was found, which should thus be related to visuo-proprioceptive conflict rather than to disembodiment [25]. In a nutshell, it is not clear yet whether the rubber hand is merely a supernumerary limb added to one's own two biological hands, or whether it somehow replaces the participant's biological hand. 
Another way to answer to the question of two-hand constraint is to investigate not the disembodiment of the biological hand, but the possibility to simultaneously embody multiple rubber hands. Ehrsson [26] reported the illusory duplication of the right hand in subjects exposed to two adjacent right rubber hands. Participants were shown two rubber hands placed side by side above their biological hand, which was hidden behind the table. After synchronous stroking of the three hands (i.e., the two rubber hands and the biological hand), they reported feeling the touch on both rubber hands. Furthermore, they reported feeling ownership towards both rubber hands. When shown a needle stubbed in the rubber hands, they showed a larger skin conductance response after synchronous than asynchronous condition.

To conclude, there may be less anatomical constraints upon the RHI that assumed by the body model hypothesis. This may even leave open the possibility of inducing the RHI for tool. Indeed, if one can embody three hands or even four, why not embody a tool as well? The illusion may be subtler to capture and take more time to induce, like in Petvoka and Ehrsson's study on laterality [22], but there is no argument yet that forbids it. However, we do not want to say that there are no constraints besides spatio-temporal congruency, or that there is no body model that plays a role for the RHI. Rather, these results invite us to be more careful and more precise in our specification of the body model. In particular, one may accommodate the possibility of embodiment of more than two hands if the body model recruited by the RHI is conceived as the representation not of the unified whole body, but rather of isolated parts of the body. On this view, all that is required for the RHI is that information drawn from vision and touch is assigned to the same object, namely, the hand. This principle is well known in the literature on multimodal integration as the assumption of unity [27]. Only signals that are assigned to the same individual are integrated together. The extent of the integration depends on the reliability of the assumption. The reliability is a function of the number of properties 
that are congruent relative to the weighting assigned to these properties (e.g., identical skin luminance is less important than identical posture). The assumption of unity requires a body model in order to identify the common source of the information drawn from the various sensory modalities, but it is a more local body model, restricted to the body part, and it is a more flexible and dynamic assumption that the body model hypothesis. Finally, one can offer a computational model of the assumption of unity in Bayesian terms [28]. What is interesting with Bayesian models is that they provide a model of understanding of how the context and the functional role (e.g., action versus perception) can affect not only multimodal integration, but also embodiment, as we shall see now with tool use.

\section{The embodiment of tool}

There are more and more studies that show that tools are integrated in the representation of one's own body. As Head and Holmes [29] noted a century ago, "Anything which participates in the conscious movement of our bodies is added to the model of ourselves and becomes part of those schemata: a woman's power of localization may extend to the feather of her hat". Since then, a number of studies have addressed the possibility that tools are embodied and it is nowadays largely accepted that tool-use affects spatial perception, motor imagery and even time perception. What is still highly debated though, is which (if a single) body representation is modified to embody tools, as well as which kind of tools (if any) can be literally embodied. Most effects that have been reported in normal and pathological cases after tool use concern multisensory processing. However, it remains unclear whether the multisensory effects can be genuinely ascribed to a change in body representation and/or in the processing of the peripersonal space (for discussion, see [30,31]. In other words, do tools enlarge the space of actions or the space of one's body, or both? And do they do so in the same way as rubber hands? 
Peripersonal space (PpS) consists of a region immediately surrounding the body (i.e., the personal space), which is characterized by a higher degree of multisensory integration between visual, tactile and auditory information as compared to farther regions of space [3234]. The representation of such a narrow sector of space is grounded on the activity of multisensory neurons that have been physiologically identified in the monkey [35] and whose human counterpart has been recently reported with imaging techniques [36]. After Iriki and colleagues' seminal work [37], showing an expansion of PpS after monkeys used a rake to retrieve distant objects, the Pps is thought to constitute a privileged interface for the body to interact with nearby objects [38,39], and particularly via the use of tools, which allow for instance to retrieve objects that would otherwise be out of reach. Echoing the basic pre-post tool-use paradigm originally devised for monkey model, it has been shown that perceptual deficits of neurological patients can be modulated (i.e., improved or worsened) during or immediately after tool-use [40-42], as can be normal perception in neurotypical participants $[31,43,44]$. However, it has recently become clear that tool-use is not necessary to obtain perceptual changes in the Pps. When asked to jointly perform visuo-tactile discrimination and reach-to-grasp tasks, neurotypical subjects manifest fast on-line changes in their perceptual capabilities that are triggered by movement onset. Importantly, free-hand actions bring about such changes, thus demonstrating multisensory plasticity is not dependent upon the use of tools $[38,39]$.

That tools can enlarge the peripersonal space is now widely accepted. But do they also affect the personal space? This is more controversial. As we shall see, there are two sets of studies, which respectively show sensory effects and motor effects. We shall argue that it is only in the latter case that tools can qualify as embodied.

It has been recently shown that visual perception is enhanced (i.e., detection reaction times are shorter) when visual stimuli are projected on the subjects' visible hand or on a similarly 
looking rubber hand, but not when projected on a 5-fingered gardening tool [45; see also 4648]. However, when subjects were re-tested after being trained in using either the fake hand or the gardening tool, their detection capabilities were improved in both cases (i.e., both after using a fake hand and a tool), bringing the authors to state "..that training makes it more likely that objects such as a fake hand or tool will be incorporated in the body schema." [45, p. 2461]. Intriguingly, important differences were nevertheless found. The training with the gardening rake improved detection for stimuli projected both on the fake hand and tool. Paradigmatic of the confusion between peripersonal and personal space, the same paper closes by stating "Altogether, these training-induced effects showing on improved detection speed can be interpreted as evidence that the peripersonal space is not fixed, but can be dynamically and rapidly re-mapped following tool-use." [45, p. 2462]. Unfortunately, no information can be derived regarding any potential sense of ownership for the fake hand or tool, as no questionnaire or other objective measures of illusion of ownerships were included in the study.

Using a slightly different approach, Press and colleagues investigated whether it is possible to identify electrophysiological markers of the embodiment of rubber hands vs. rubber objects [49]. An enhanced early (N140) somatosensory component was indeed found after synchronous vs. asynchronous visuo-tactile training (typically used in RHI paradigms). This enhancement, however, was present irrespective of whether subjects were looking at the rubber hand, or a non hand-shaped rubber object. Given its unspecific feature, this somatosensory component may actually represent the counterpart of the multisensory integrative component of the RHI, which is told to be necessary, but not sufficient for sense of ownership to emerge. Again, no subjective or objective indices of ownership were included in this study, thus leaving any possible parallel with the RHI studies a bit indirect. In addition, possibly because of the methodological differences with respect to the study by Kao \& 
Goodale [45], here visual discriminative performance was not found to be enhanced when visual stimuli were presented on rubber hands compared to rubber objects, rendering any possible link with the features of Pps even more speculative.

In a nutshell, tools use alters the processing of sensory events in the peripersonal space and in the personal space. However, these results per se do not show that tool use alters the representation of one's body, less even of the body schema (representation of one's body for action, see section 3 for more details), although this conclusion has been repetitively drawn. In the attempt to test directly whether tool-use dynamically modifies body representations, Cardinali and colleagues [50] recently analysed the spatio-temporal profile of the movements in neurotypical participants performing one of the simplest motor acts, namely grasping an object with their hand. Subjects were then engaged in the use of a commercial mechanical grabber to grasp the same object. When subsequently re-tested while reaching to grasp with their hand alone, the kinematics of participants' transport phase of their movements was significantly modified. Not only they took a longer time to achieve the maximal acceleration, velocity and deceleration during the approaching phase to the target object, but the maximal amplitude of these parameters was reduced. These changes were selective for the reaching phase, as the pre-shaping of the hand to accurately grasp the object was not affected. When considered with respect to the length of the participants' arm, this pattern of results corresponds to the difference that is naturally present between long- and short-armed subjects: 'long-arm' subjects will show longer latencies and reduced amplitudes compared to 'shortarm' subjects when grasping the same target object. This finding suggests not only that tooluse does indeed modify the body representation for action (i.e., the body schema, see section 3), but also that it does so by increasing the represented length of the subject's arm. If this were true, such a personal change would impact the kinematics of other actions that are sensitive to the arm length, even if they were not explicitly trained during the tool-use training 
session. For example, if tool-use 'extends' the arm length, this should generalize to movements such as pointing on top of objects, instead of grasping them, as the pointing movement is devoid of the grip-formation component of the movement (not affected by tooluse), but contains the transport component of the trained movement (selectively affected by tool-use and sensitive to arm-length). This prediction was entirely confirmed by further results from our study: subjects showed a virtually identical pattern of post tool-use changes in kinematics, irrespective of whether they grasped or merely pointed the target objects [50]. What should be additionally noted is that these changes take place rapidly and without requiring learning processes. Contrary to typical sensorimotor adaptation to prisms or force fields [51,52], no trace of learning was detected in the kinematics of subjects during the four blocks of tool-use, and this despite the fact that none of them have had previous experience with that given mechanical grabber. Humans are proficient tool-users, it would make an obvious phylogenic advantage to have developed a body representation that allows one to immediately "tune" the motor control requirements to the physical and mechanical characteristics of a novel tool.

Overall, the effects on movement kinematics reported above can be taken to say tool-use modifies the motor side of the body representation. Does this imply that the representation of the body morphology is affected also when testing unconscious and implicit aspects of body knowledge such as the way arm-length is represented at a somatosensory level? To answer this question, we asked neurotypical participants to point to tactually stimulated parts (middle finger-tip, wrist, elbow) of their right forearm (involved in tool-use) with their right forefinger (not involved in tool-use). To derive subjects' internally represented length of their hand and forearm, we computed the distance between pointing to the middle finger-tip and wrist, and between wrist and elbow. These distance measures were then compared before and immediately after an identical tool-use session, revealing that after tool-use subjects pointed 
to locations that were farther apart, as if their arm were physically longer (see, for details, [50]).

There are therefore not only perceptual, but more profound motor and somatosensory consequences when one uses a tool. In this respect, we suggested this is a direct demonstration that tool-use does indeed change what we have so far called the body schema. Even more intriguingly, the effects of this plastic modification in the body schema seem to last long enough to be detected after the change itself has occurred, most likely during the tool-use phase. We believe that, in contrast to the previous putative changes of the body schema, it is when the consequences of using a tool affect the representation of our acting body that the tool "becomes a part" of the body. This direct measure of changes in the body schema may thus provide a new sensitive test to verify whether changes in the body schema invariably imply changes in the multisensory processing of peripersonal space, or they can be dissociated [30].

\section{The manifold of embodiment}

To recap, the question we started from was what can be embodied. It is hardly intuitive that one can embody anything. There must be some constraints, but which ones? Although the RHI may seem at first sight highly constrained, we showed that the anatomy of a template human body does not always need to be respected. Furthermore, we showed that tools do not merely enlarge the space of action, but are really integrated in the representation of one's body. Hence, both rubber hands and tools can be embodied, but one still needs to account for their differences. Do they result merely from distinct triggering mechanisms, a perceptual mechanism and a motor mechanism, or do they reflect distinct types of embodiment? 
Most versions of the RHI are purely perceptual, both because of the input (i.e. passive tactile stimulation) and because of the task (i.e. introspective report and perceptual judgment of the hand location). On the other hand, the embodiment of tools results from active training and use. One may then suggest that perceptual trigger and motor trigger cause two functionally distinct types of embodiment. An object is perceptually embodied if it is processed as if it were a part of one's body for perceptual tasks. An object is motorically embodied if it is processed as if it were a part of one's body for motor tasks. Another way to characterize this distinction is in terms of the representations of the body that they involve. It is classically assumed that there are at least two types of body representations [53-55]. The body schema consists in sensorimotor representations based on afferent and efferent information, which guide bodily movements. The body image groups all the other representations about the body that are not used for action, whether they are perceptual, conceptual or emotional (body percept, body concept and body affect, cf. [56]). Although controversial (for review, see [57]), this distinction may be of interest to analyse the differences between rubber hand embodiment and tool embodiment. Perceptual embodiment consists in representing the object within the body image, whereas motor embodiment consists in representing the object within the body schema. We are far now from the body model hypothesis. Rather than a template of a human body within which an object can be integrated or not, there are two distinct body representations, each with their own functional role, but also possibly each with their own dynamics and their own constraints.

Perceptual embodiment and motor embodiment are always associated when it comes to one's biological body, even for parts of the body that cannot move. Indeed, one needs to take into account the boundaries of the complete body and its peripersonal space if one does not want to bump into objects. Yet, perceptual embodiment and motor embodiment can be dissociable, as shown by the following studies on the RHI and on tools. 
As said before, most RHI studies ask participants to report the location of their unseen stimulated hand. The measured proprioceptive drift reflects perceptual embodiment of the rubber hand. But is the rubber hand also motorically embodied? In questionnaires, participants report low feeling of control over the rubber hand [23]. This is confirmed by the fact that action is immune to the RHI [58]. Participants were asked to indicate the felt position of their hand by providing motor responses (e.g., reaching the stimulated hand with the contralateral hand, reaching the contralateral hand with the stimulated hand, and grasping a stick with the two hands). We found no significant difference in the kinematics after asynchronous and synchronous stimulations. In other words, there was no proprioceptive drift for any of the motor responses. Even more convincing, and maybe more surprising, is the independence of the perceptual and motor responses. When participants were asked a second time to give a perceptual judgment about their hand location after having moved, they were still sensitive to the RHI. One way to interpret these results is that the rubber hand is perceptually embodied, but not motorically.

The distinction between the two types of embodiment cannot be reduced to the distinction between the two types of triggering mechanism, multimodal integration versus action. Indeed, some versions of the RHI studies use active tactile stimulation, rather than passive (e.g. participants actively stroked the bristles of a toothbrush with their unseen biological hand while seeing the rubber hand performing the same movement, synchronously or not). This motor version of the RHI reduces the extent of the RHI [59], but for all that, it does not increase motor embodiment [60]. In addition, motor embodiment may be more constrained than perceptual embodiment. A recent study using active stimulation and two rubber hands replicated Ehrsson's results, showing perceptual embodiment of the two rubber hands, but also found a lack of motor embodiment of the two rubber hands [61]. When asked to reach a target with their hand, the trajectory was not deviated when the three hands were stroked 
synchronously, showing thus that the motor system used the coordinates of the biological hand to plan the movement. To conclude, it is not because embodiment is caused by action that it has consequences for action.

We have seen that the rubber hand can be perceptually embodied without being motorically embodied. Conversely, we would like to suggest that tools can be motorically embodied without being perceptually embodied. A recent paper by Povinelli and colleagues [62] argues that we do not literally processed tools as if it were part of our body because we use tools in situations where we would not use our own body, for instance like using a stick to stoke a campfire, or stir a pot of boiling soup with a wooden spoon. They showed that even chimpanzees keep discrete representations of their own hands and of the tools such that they select to use a tool, rather than their hands, when acting in potentially hazardous circumstances located within reach. However, there is a different way to interpret their results, namely, that the tools are embodied but only motorically, and not perceptually. In other words, the body image is said to include not only body percept, but also body affect. Numerous RHI studies have shown that if one threatens the rubber hand with a hammer or a needle, participants react affectively as measured by the increase of skin conduction reaction, as if their own hand was threatened. Hence, it seems that an object needs to be perceptually embodied for one to react affectively towards it. The fact that chimpanzees and humans prefer to use tools in dangerous situations may show that the tools are not perceptually embodied, although motorically embodied. Since the body schema can be conceived of as the representation the brain uses to plan and execute actions, and tools are actively manipulated, it becomes intuitive to relate tool embodiment to the body schema instead of the body image [63]. This has been confirmed by the results previously described [50]. The privileged link to action is also reflected in the fact that tools alter the peripersonal space, that is, the space of action. Alternatively, one may argue that one selects to use parts of the body that are the best 
fit for the task, and the truth is that tools are better fit than human or chimp hands in these situations. This has nothing to do with keeping tools outside the representation of one's body.

To conclude, perceptual embodiment and motor embodiment may follow different rules, based on the functional roles of the body representations within which external objects are integrated. Arguably, what is required for action is not the same as what is required for perception. This is not necessarily to say that motor embodiment may be more flexible than motor embodiment. True, tools can be motorically embodied, while it is still an open question whether it can be perceptually embodied. On the other hand, multiple rubber hands can be perceptually embodied, while they cannot be motorically embodied.

\section{Conclusion: a partial embodiment}

While most of the literature focuses exclusively on tools or on rubber hands, we think that it is a more fruitful approach to compare and integrate the results in both domains. This may indeed help us to understand what is at stake in embodiment. In particular, it is of clinical interest in order to improve the quality of embodiment of allograft and prostheses in amputees. We would like to conclude with a last remark. Until now, we have assumed that an object is embodied if it is processed as if it were a part of one's body. But this description seems to imply that all properties of the object are processed as if they were properties of one's own body. And this is not true. First, we have seen that this depends on the tasks, whether perceptual or motor. But even within perceptual embodiment, not all the perceptual properties of the objects are necessarily processed as if they were properties of one's body. For instance, the location of the rubber hand is processed as if it were the location of one's own hand, but not its visual appearance. Hence, the rubber hand is not embodied to the same extent as one's biological hand. This difference may explain why the rubber hand does not 
replace the biological hand: the rubber hand is not embodied enough to take over the biological hand. Similarly, motor embodiment can be more or less partial. Tools alter the representation of one's body for action, but only for a short period of time. But action requires the representation of one's long-term bodily parameters (e.g., size, strength, etc.) to be flexible: it should quickly and temporarily change to fit the novel needs imposed by a given tool. It should also change to allow for a quick recovery of the 'default' parameters, probably stored in a longer-term body schema when freed from novel constraints. We suggest prolonged, proficient tool-use may neurally translate into either more stable changes in the default parameters (longer-lasting plastic changes), or rapid contextually-based access to separate representations (default $=$ standard body vs. augmented $=$ std. body + tool). We would like to suggest that the lack of long-term motor embodiment explains the absence of feeling of ownership towards tools [64]. 


\section{Acknowledgements}

This work was supported by the ANR grants No. JCJC06_133960, RPV08085CSA and R08118CS and the INSERM AVENIR grant No. R05265CS.

\section{References}

1 Butler, S. Erewhon. London: Penguin Classics, 1872

2 Makin TR, Holmes NP, Ehrsson HH. On the other hand: dummy hands and peripersonal space. Behav Brain Res 2008; 191:1-10.

3 Botvinick, M. Neuroscience. Probing the neural basis of body ownership. Science 2004; 305:782-783.

4 De Preester H, Tsakiris M. Body-extension versus body-incorporation: Is there a need for a body-model? Phen Cog Sciences 2009; 8: 307-319.

5 Tsakiris M, Carpenter L, James D, Fotopoulou A. Hands only illusion: multisensory integration elicits sense of ownership for body parts but not for non-corporeal objects. Exp Brain Res 2010; 204:343-352.

6 Haans A, Ijsselsteijn WA, de Kort YA. The effect of similarities in skin texture and hand shape on perceived ownership of a fake limb. Body Image 2008; 5:389-394.

7 Tsakiris M. My body in the brain: a neurocognitive model of body-ownership. Neuropsychologia 2010; 48:703-712.

8 Armel KC, Ramachandran VS. Projecting sensations to external objects: evidence from skin conductance response. Proc Biol Sci 2003; 270:1499-1506.

9 Costantini M, Haggard P. The rubber hand illusion: sensitivity and reference frame for body ownership. Conscious Cogn 2007; 16: 229-240.

10 Tsakiris M, Haggard P. The rubber hand illusion revisited: visuotactile integration and self-attribution. J Exp Psychol Hum Percept Perform 2005; 31: 80-91.

11 O'Shaughnessy B. The will: dual aspect theory. Cambridge: Cambridge University Press, 1980 .

12 Sirigu A, Grafman J, Bressler K, Sunderland T. Multiple representations contribute to body knowledge processing. Evidence from a case of autotopagnosia. Brain 1991; 114: 629-642.

13 Schwoebel J, Coslett HB. Evidence for multiple, distinct representations of the human body. J Cogn Neurosci 2005; 17: 543-553.

14 Botvinick M, Cohen J. Rubber hands 'feel' touch that eyes see. Nature 1998; 391: 756.

15 Shimada S, Fukuda K, Hiraki K. Rubber hand illusion under delayed visual feedback. PLoS One 2009; 4:e6185.

16 Lloyd DM. Spatial limits on referred touch to an alien limb may reflect boundaries of visuo-tactile peripersonal space surrounding the hand. Brain Cogn 2007; 64:104-109.

17 Pavani F, Spence C, Driver J. Visual capture of touch: out-of-the-body experiences with rubber gloves. Psychol Sci 2000; 11: 353-359.

18 Pavani F, Zampini M. The role of hand size in the fake-hand illusion paradigm. Perception 2007; 36: 1547-1554. 
19 Longo MR, Schüür F, Kammers MP, Tsakiris M, Haggard P. Self awareness and the body image. Acta Psychol (Amst) 2009; 132: 166-172.

20 Slater M, Spanlang B, Sanchez-Vives MV, Blanke O. First person experience of body transfer in virtual reality. PLoS One 2010; 5: e10564.

21 Ocklenburg S, Ruther N, Peterburs J, Pinnow M, Gunturkun O. Laterality in the rubber hand illusion. Laterality 2010; 1: 1-14.

22 Petkova VI, Ehrsson HH. When right feels left: referral of touch and ownership between the hands. PLoS One 2009; 4: e6933.

23 Longo MR, Schüür F, Kammers MP, Tsakiris M, Haggard P. What is embodiment? A psychometric approach. Cognition 2008; 107: 978-998.

24 Moseley GL, Olthof N, Venema A, Don S, Wijers M, Gallace A, Spence C. Psychologically induced cooling of a specific body part caused by the illusory ownership of an artificial counterpart. PNAS 2008; 105: 13169-13173.

25 Folegatti A, de Vignemont F, Pavani F, Rossetti Y, Farnè A. Losing one's hand: visualproprioceptive conflict affects touch perception. PLoS One 2009; 4: e6920.

26 Ehrsson HH. How many arms make a pair? Perceptual illusion of having an additional limb. Perception 2009; 38: 310-312.

27 Welch RB, Warren DH. Immediate perceptual response to intersensory discrepancy. Psychol Bull 1980; 88: 638-667.

28 Ernst M. A Bayesian view on multimodal cue integration. In: Knoblich G, Thornton IM, Grosjean M, Shiffrar M eds. Human Body Perception From The Inside Out. New York: Oxford University Press, 2006.

29 Head H, Holmes H G. Sensory disturbances from cerebral lesions. Brain 1911-1912; 34: $102-254$

30 Cardinali L, Brozzoli C, Farnè A. Peripersonal space and body schema: two labels for the same concept? Brain Topogr 2009; 21: 252-260.

31 Holmes NP, Spence C. The body schema and the multisensory representation(s) of peripersonal space. Cogn Process 2004; 5: 94-105.

32 Brozzoli C, Demattè ML, Pavani F, Frassinetti F, Farnè A. Neglect and extinction: within and between sensory modalities. Restor Neurol Neurosci 2006; 24: 217-232.

33 Farnè A, Demattè ML, Làdavas E. Neuropsychological evidence of modular organization of the near peripersonal space. Neurology 2005; 65: 1754-1758.

34 Farnè A, Iriki A, Làdavas E. Shaping multisensory action-space with tools: evidence from patients with cross-modal extinction. Neuropsychologia 2005; 43: 238-248.

35 Rizzolatti G, Scandolara C, Matelli M, Gentilucci M. Afferent properties of periarcuate neurons in macaque monkeys. I. Somatosensory responses. Behav Brain Res 1981; 2: 125146.

36 Sereno MI, Huang RS. A human parietal face area contains aligned head-centered visual and tactile maps. Nat Neurosci 2006; 9: 1337-1343.

37 Iriki A, Tanaka M, Iwamura Y. Coding of modified body schema during tool use by macaque postcentral neurones. Neuroreport 1996; 7: 2325-2330. 
38 Brozzoli C, Pavani F, Urquizar C, Cardinali L, Farnè A. Grasping actions remap peripersonal space. Neuroreport 2009; 20: 913-917. Erratum in: Neuroreport 2010; 21: 156.

39 Brozzoli C, Cardinali L, Pavani F, Farnè A. Action-specific remapping of peripersonal space. Neuropsychologia 2010; 48: 796-802.

40 Berti A, Frassinetti F. When far becomes near: remapping of space by tool use. $J$ Cog Neurosci 2000; 12: 415-420.

41 Farnè A, Làdavas E. Dynamic size-change of hand peripersonal space following tool use. Neuroreport 2000; 11: 1645-1649.

42 Maravita A, Clarke K, Husain M, Driver J. Active tool use with the contralesional hand can reduce cross-modal extinction of touch on that hand. Neurocase 2002; 8: 411-416.

43 Maravita A, Spence C, Kennett S, Driver J. Tool-use changes multimodal spatial interactions between vision and touch in normal humans. Cognition 2002; 83: B25-B34.

44 Witt JK, Proffitt DR, Epstein W. Tool use affects perceived distance, but only when you intend to use it. J Exp Psychol: HPP 2005; 31: 880-888.

45 Kao KL, Goodale MA. Enhanced detection of visual targets on the hand and familiar tools. Neuropsychologia 2009; 47: 2454-2463.

46 Hari R, Jousmaki V. Preference of personal to extrapersonal space in a visuomotor task. $J$ Cog Neurosci 1996; 8: 305-307.

47 Whiteley L, Kennett S, Taylor-Clarke M, Haggard P. Facilitated processing of visual stimuli associated with the body. Perception 2004; 33: 307-314.

48 Revol P, Farnè A, Pisella L, Holmes NP, Imai A, Susami K, Koga K, Rossetti Y. Optokinetic stimulation induces illusory movement of both out-of-the-body and on-thebody hand-held visual objects. Exp Brain Res 2009; 193: 633-638.

49 Press C, Heyes C, Haggard P, Eimer M. Visuotactile learning and body representation: An ERP study with rubber hands and rubber objects. J Cog Neurosci 2008; 20: 312-323.

50 Cardinali L, Frassinetti F, Brozzoli C, Urquizar C, Roy AC, Farnè A. Tool-use induces morphological updating of the body schema. Curr Biol 2009; 19: R478-479. Erratum in: Curr Biol 2009; 19: 1157.

51 Pisella L, Rode G, Farnè A, Tilikete C, Rossetti Y. Prism adaptation in the rehabilitation of patients with visuo-spatial cognitive disorders. Curr Op Neurol 2006; 19: 534-542.

52 Shadmehr R, Mussa-Ivaldi FA. Adaptive representation of dynamics during learning of a motor task. J Neurosci 1994; 14: 3208-3224.

53 Paillard J. Body schema and body image: a double dissociation in deafferented patients. In: Gantchev GN, Mori S, Massion J eds. Motor control, today and tomorrow. 1999.

54 Gallagher S. How the body shapes the mind. Oxford, Oxford University Press, 2005.

55 Dijkerman HC, de Haan EH. Somatosensory processes subserving perception and action. Behav Brain Sci 2007; 30: 189-201.

56 Gallagher S. Body schema and intentionality. In: Bermudez JL, Marcel A, Eilan N eds. The body and the self. Cambridge (Mass.): MIT Press, 1995.

57 de Vignemont F. Body schema and body image--pros and cons. Neuropsychologia 2010; 48: 669-680. 
58 Kammers MP, de Vignemont F, Verhagen L, Dijkerman HC. The rubber hand illusion in action. Neuropsychologia 2009; 47: 204-211.

59 Tsakiris M, Prabhu G, Haggard P. Having a body versus moving your body: How agency structures body-ownership. Conscious Cogn 2006; 15: 423-432.

60 Kammers MP, Longo MR, Tsakiris M, Dijkerman HC, Haggard P. Specificity and coherence of body representations. Perception 2009; 38: 1804-1820.

61 Newport R, Pearce R, Preston C. Fake hands in action: embodiment and control of supernumerary limbs. Exp Brain Res 2010; 204: 385-395.

62 Povinelli DJ, Reaux JE, Frey SH. Chimpanzees' context-dependent tool use provides evidence for separable representations of hand and tool even during active use within peripersonal space. Neuropsychologia 2010; 48: 243-247.

63 Maravita A, Iriki A. Tools for the body (schema). TICS 2004; 8: 79-85.

64 de Vignemont F. Habeas corpus: the sense of ownership of one's body. Mind and Language. 2007. 